\title{
21 Year-old Male Dies when Struck in the Head with a Track Hoe Bucket
}

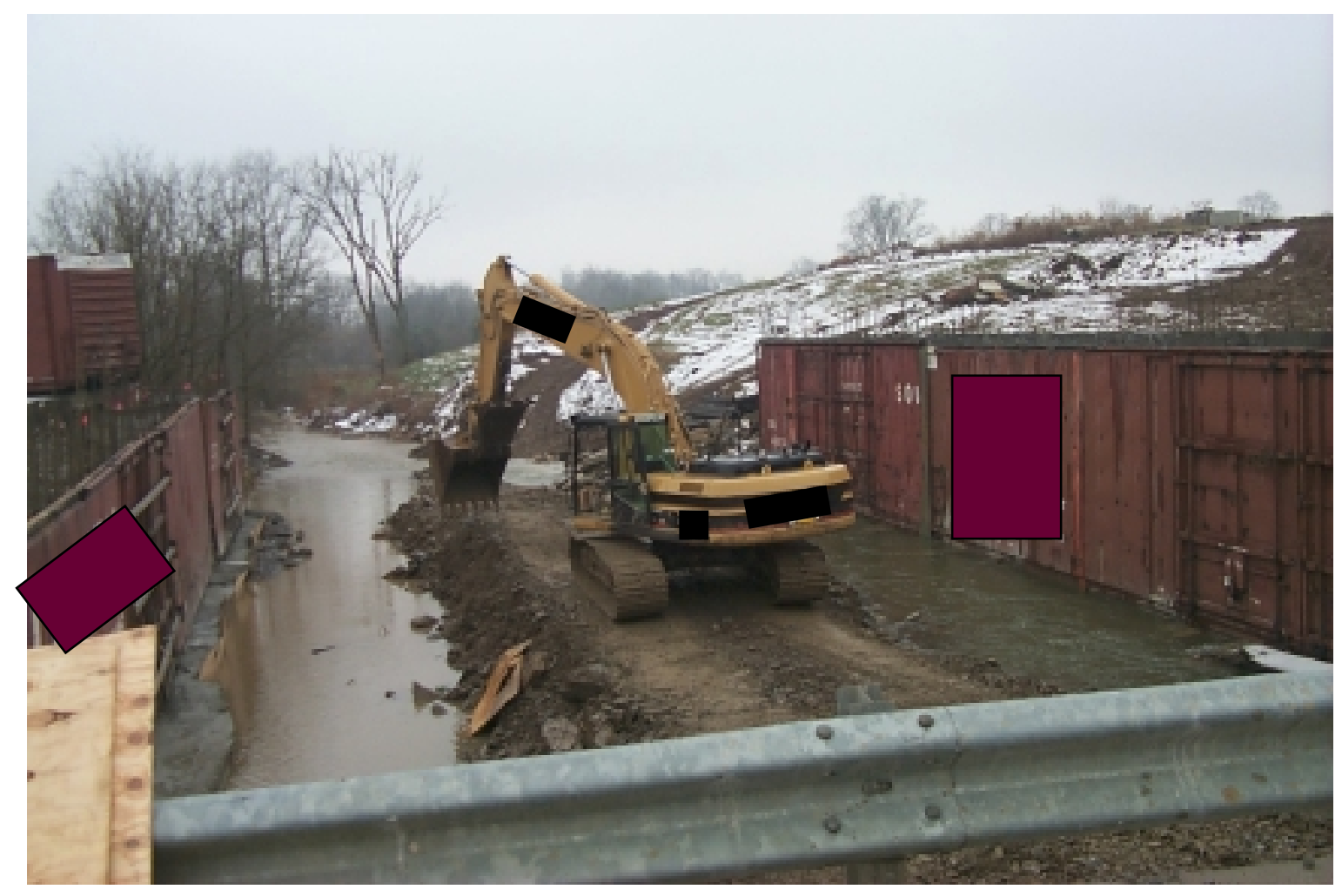

\section{Incident Number: $\quad 02 K Y 106$ \\ Date of Incident: $\quad$ November 22, 2002 \\ Report Release Date: June 17, 2003}

Kentucky Fatality Assessment and Control Evaluation Progran Kentucky Injury Prevention and Research Center 333 Waller Avenue

Suite 202

Lexington, Kentucky 40504

Phone: 859-323-2981

Fax: 859-257-3909

www.kiprc.uky.edu

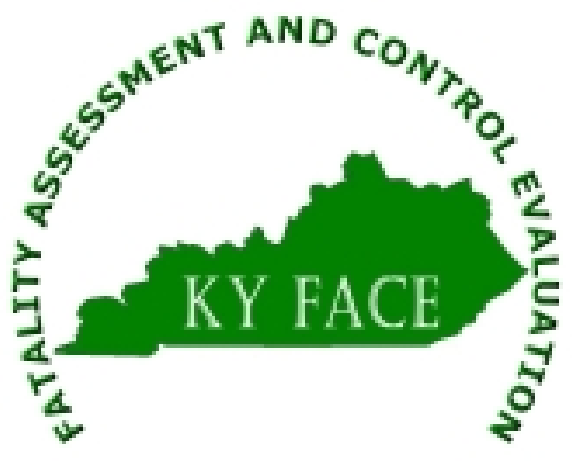




\section{Kentucky Fatality Assessment and Control Evaluation (FACE) Program Incident: 02KY106 \\ Release Date:}

Subject: 21 Year-old Male Dies when Struck in the Head with a Track Hoe Bucket

\section{Summary}

On November 22, 2002, a 21-year-old male laborer died after being hit in the head with the bucket of a track hoe. He was wearing a safety helmet at the time of the incident. There were six to seven workers at the job site when the incident occurred. The work crew was pouring the footing for a retaining wall as part of a bridge for a private runway being built. The concrete form collapsed, trapping one worker and almost trapping two others. The decedent had left to retrieve a shovel to help free the trapped co-worker. As he retrieved the shovel, he walked into a blind spot of the track hoe operator at the same time another worker asked the track hoe operator if there was a chain in the cab of the track hoe. The operator looked down at the floor and as he did so, his hand slightly moved the hand control causing the bucket to move, thus striking the decedent. He was transported to a hospital where he was declared dead by the coroner from blunt force injuries to the head.

In order to prevent similar incidents from occurring, the Kentucky Fatality Assessment and Control Evaluation program recommends:

- A hazard assessment of the work area should be performed every time work conditions change. Workers should not be in a blind spot of heavy equipment operators without the operator's knowledge. When blind spots are identified, a spotter should be used.

- During emergency situations employ safe work practices.

\section{Introduction and Background}

On November 26, 2002, through online newspaper surveillance, the Kentucky Fatality Assessment and Control Evaluation program became aware of an occupational fatality, which had occurred on November 22, 2002. The coroner and police were contacted the same day. A site visit was made on December 11, 2002 and interviews with the human resource and safety directors were conducted.

The decedent was a 21-year-old male who had been working for the company for nine months. The decedent had experience working for the state and county road departments.

The company began operations in 1973 and had expanded into a conglomerate of 17 divisions and employed approximately 545 workers. All divisions of the conglomerate required its employees to follow Department of Transportation safety regulations. All employees were required to wear appropriate safety equipment such as reflective vests, hard hats and appropriate work boots. Safety and job training were a part of the entire company culture. Hazard materials training is required for all job site and field personnel. Superintendents hold mandatory weekly toolbox talks and attendees are required to sign an attendance sheet. These signed sheets are 
sent to the home office where they are filed. The safety manual was made available for inspection and was found to be comprehensive in scope.

\section{Investigation}

The company was building a mile-long private runway for the company plane. Company construction laborers were assigned to build the runway. The job entailed building a runway on pasture land. This involved clearing and grading land, laying rock and pouring concrete. A section of the runway traversed a creek, which needed to be bridged. Retaining walls and supports were made of metal forms filled with concrete. The metal forms had metal ties inserted horizontally and rebar vertically to join the sides together. Concrete was then poured into the metal form in four-foot high sections.

The decedent laborer had been assigned to help build the private airfield. On the afternoon of the incident, the work crew of 6 to 7 employees was pouring a concrete footer when one of the sides of the form collapsed. Three employees were in the path of the flowing concrete. One employee was trapped up to his waist and the other two managed to escape.

In efforts to free the trapped worker from the cement, the remainder of the crew decided to use a track hoe that was on site and shovels. The track hoe was driven to the area of the trapped coworker to help remove some of the cement and the operator was waiting for instructions. While the operator waited, he locked out the control mechanisms (two joy sticks) so the bucket could not be moved. The decedent obtained a shovel to aid in freeing his coworker from the cement. As he retrieved the shovel, he had positioned himself between the wall of the retaining form and the bucket of the track hoe. In this location the decedent was out of sight of the track hoe operator.

After the situation was assessed, the operator unlocked the controls so he could begin to remove some of the escaped cement. At that moment, a laborer on the ground asked the operator if there was a chain in the cab of the track hoe. When the operator looked down at the floor to see if there was a chain or not, his hand brushed one of the unlocked joy sticks and the bucket moved, which hit the laborer in the head.

Realizing an employee had been injured, the job foreman radioed the shop manager to call emergency rescue to the scene. After contacting emergency rescue services, the shop manager informed the safety director of the incident. The safety director arrived at the scene before emergency rescue personnel and requested the decedent be airlifted to the hospital. An ambulance, the fire department and sheriff deputy arrived at the scene. Emergency medical personnel checked the decedent for pulse rate, oxygen levels, performed cardiopulmonary resuscitation and began intravenous solution. The patient was transported via ambulance to a nearby hospital where he was pronounced dead.

\section{Cause of Death}

The Medical Examiners report listed the cause of death as "due to blunt force injuries to the head". 


\section{Recommendations with Discussions}

Recommendation No. 1: A hazard assessment of the work area should be performed every time work conditions change. Workers should not be in a blind spot of heavy equipment operators without the operator's knowledge. When blind spots are identified, a spotter should be used.

A thorough hazard assessment of the job site should be performed whenever conditions change. This would have included taping off the area the track hoe was working in. When working around heavy equipment, an evaluation of potential blind spots should be included in this hazard assessment. Potential blind spots would have been identified and employees not allowed in that area. When workers find themselves in blind spots of equipment operators, there should be a spotter who is in communication with the equipment operator to communicate with the operator while a worker is performing job functions in the operator's blind spot.

Recommendation No. 2: During emergency situations employ safe work practices.

The company had trained its work force in safety procedures. Emergency work procedures should be addressed and routinely reinforced along with normal work procedures.

\section{Side Note:}

KY FACE spoke with a track hoe manufacturer regarding installing voice activated lockout for the controls, or installing a video camera on the arm that could send a video image of the blind spots to the operator. The consensus of adding these devices was that there is too much noise in the cab for a voice-activated control to function properly. If a video camera were installed, the operator would be looking at the monitor and not at what the arm of the track hoe was doing. The manufacturer did not want any distractions for the operator. According to the manufacturer, the area of track hoe operations was to be taped off to limit access to the work area.

Keywords - track hoe, hard hat, joystick, blind spot

The Kentucky Fatality Assessment \& Control Evaluation Program (FACE) is funded by a grant from the Centers for Disease Control and the National Institute of Safety and Health. FACE's purpose is to aid in the research and prevention of occupational fatalities by evaluating events leading to, during, and after a work related fatality. Recommendations are made to aid employers and employees to have a safer work environment. Current focuses of the program are occupational fatalities involving: construction, machinery, immigrant workers (particularly Hispanics) and youth.

For more information about FACE and KIPRC, please visit our website at: www.kiprc.uky.edu 


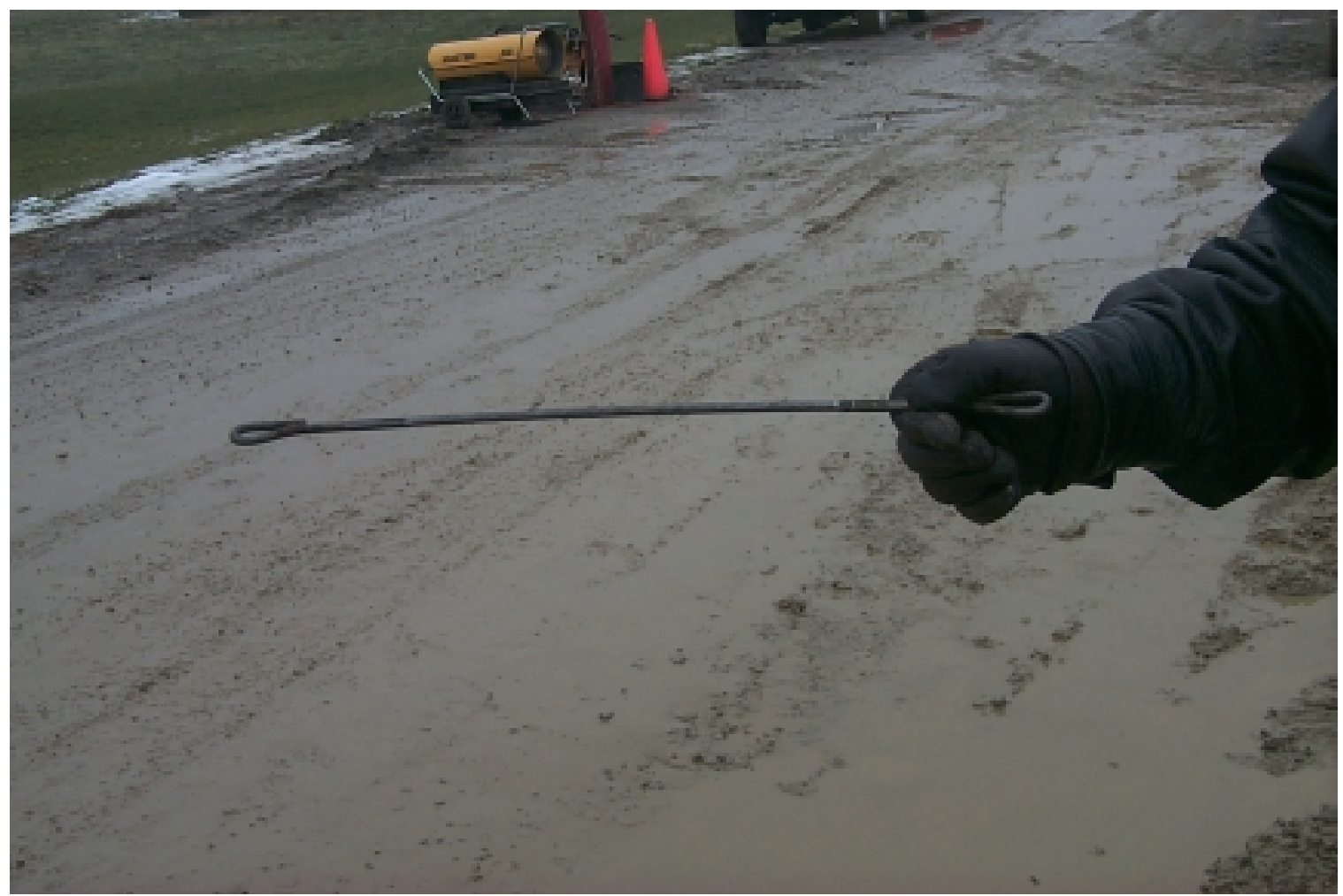

Picture of wire used for horizontal stability of concrete form.

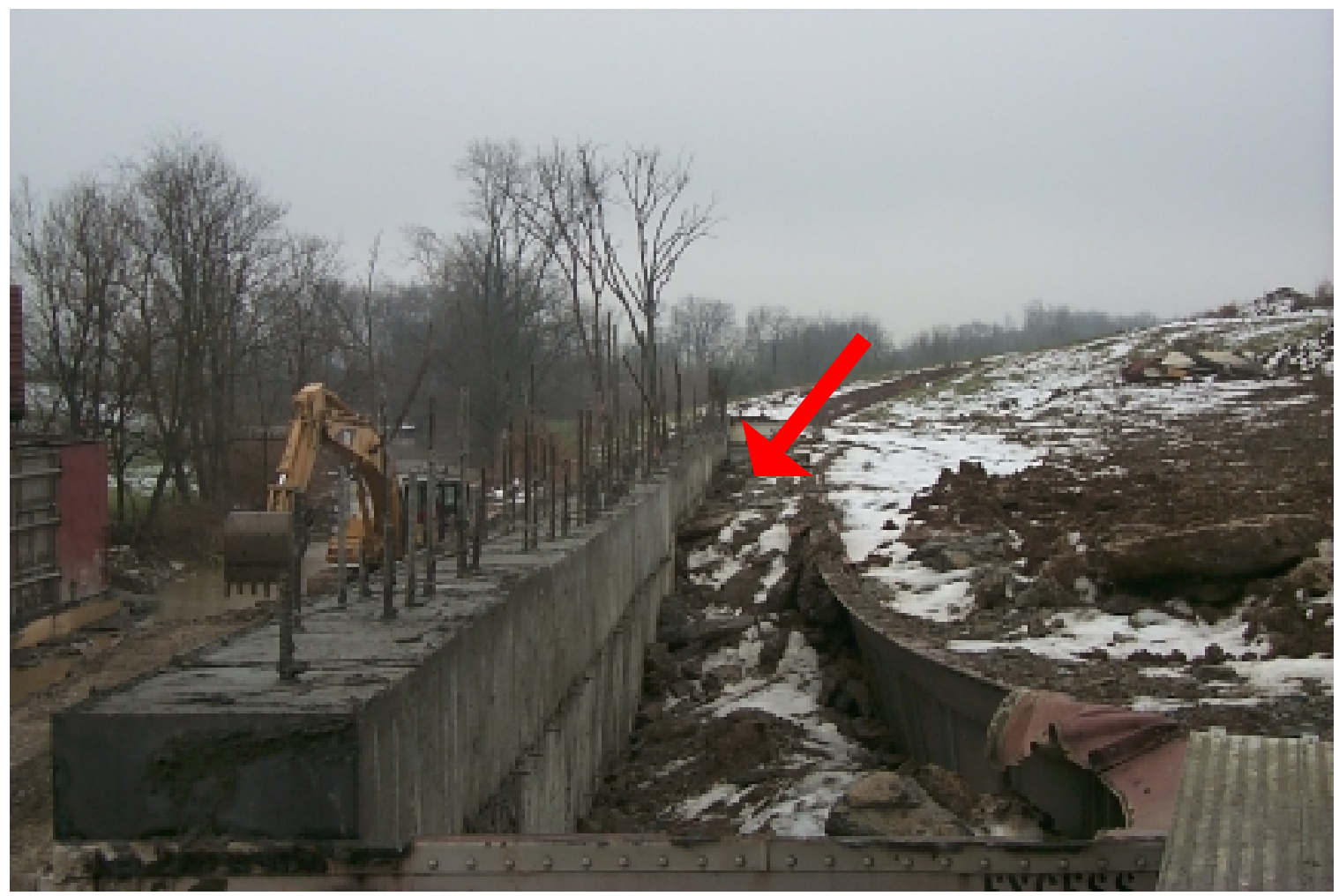

Location where incident occurred. Actual location is at the bottom of this form. 


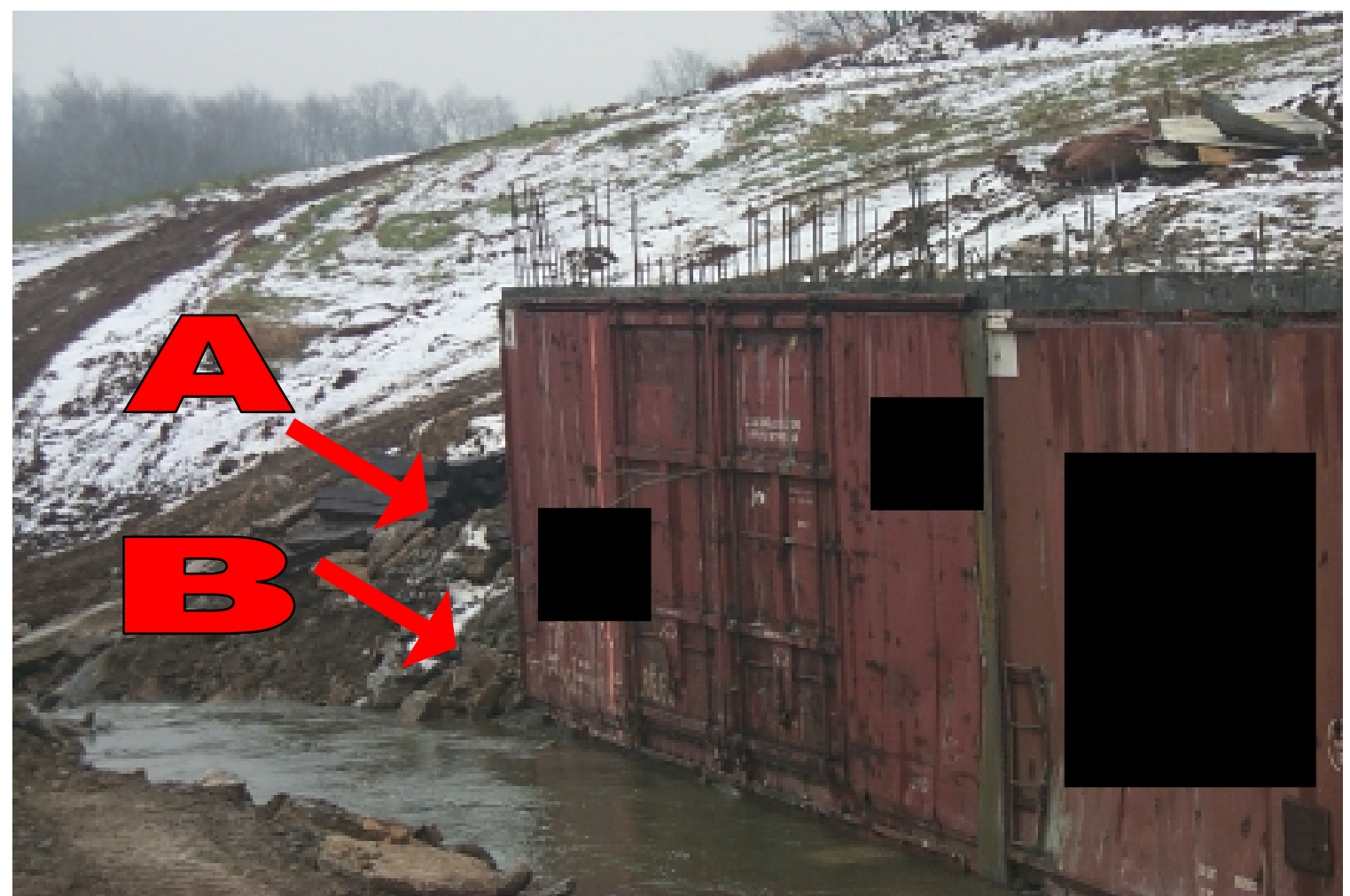

A: Track hoe location at time of incident

B: Location of Decedent at time of incident

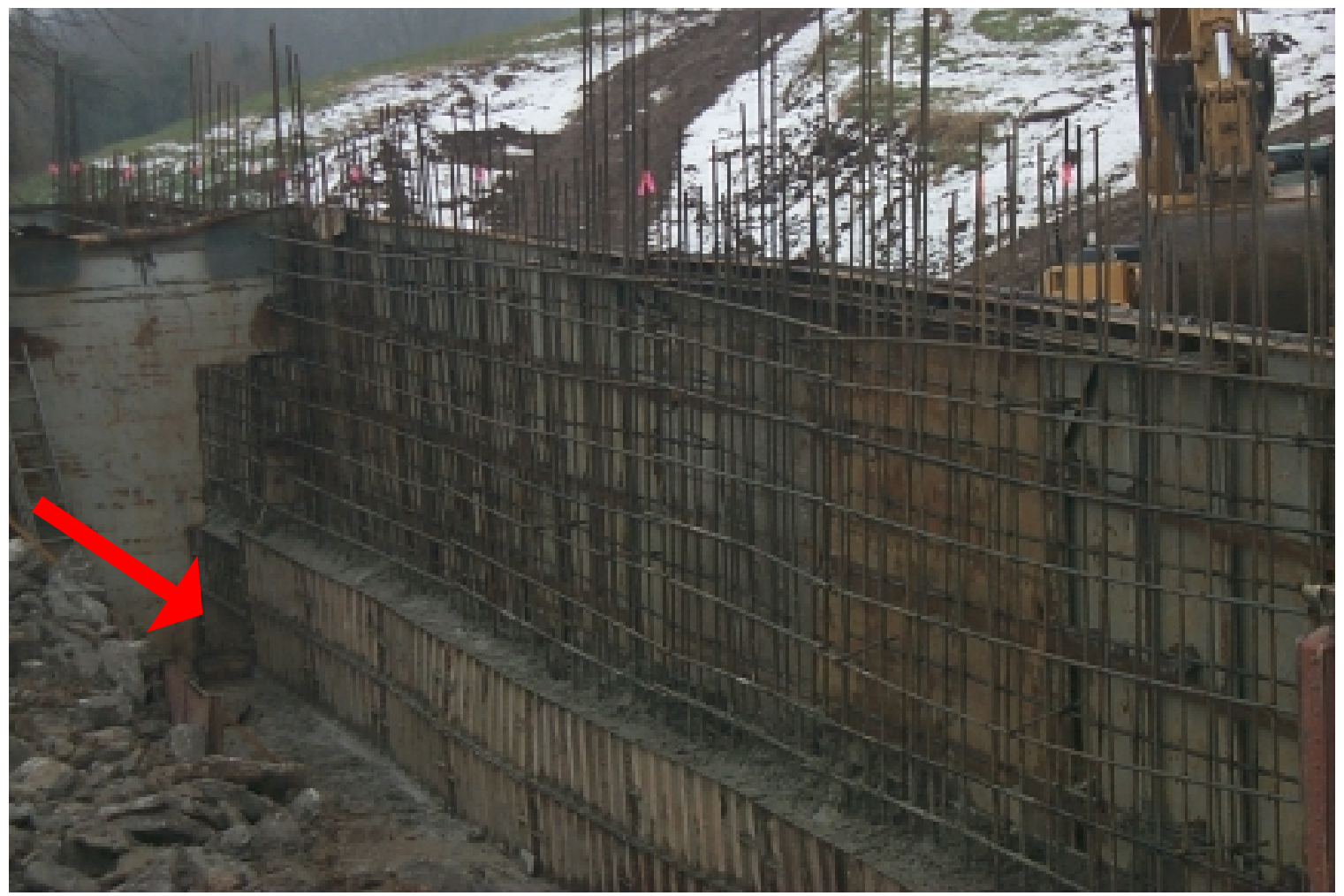

Picture of the opposite form being poured. This is how the other side looked when forms broke, trapping a worker waist high in cement. 


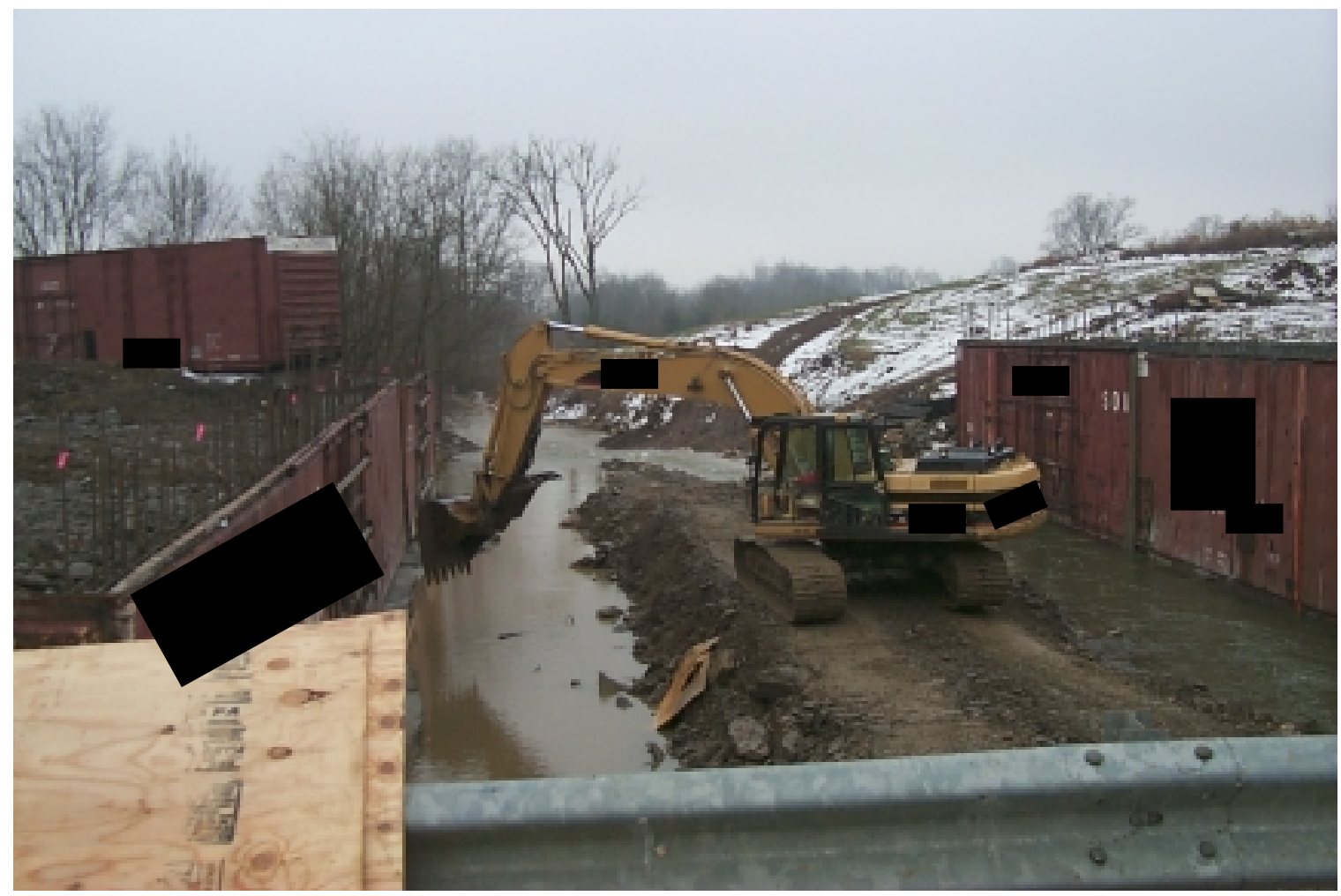

Picture of track hoe used to pull concrete away from worker. 